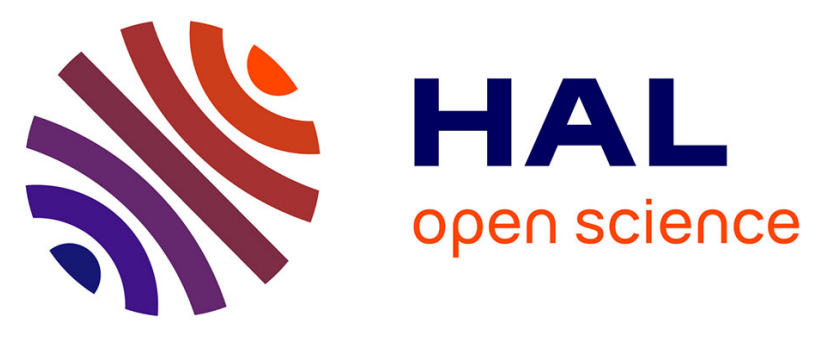

\title{
The Mediterranean fishery management: A call for shifting the current paradigm from duplication to synergy
}

\author{
Massimiliano Cardinale, Francesco Colloca, Angelo Bonanno, Giuseppe \\ Scarcella, Enrico Arneri, Angélique Jadaud, Claire Saraux, Salvatore Aronica, \\ Simona Genovese, Marco Barra, et al.
}

\section{To cite this version:}

Massimiliano Cardinale, Francesco Colloca, Angelo Bonanno, Giuseppe Scarcella, Enrico Arneri, et al.. The Mediterranean fishery management: A call for shifting the current paradigm from duplication to synergy. Marine Policy, 2021, 131, pp.104612. 10.1016/j.marpol.2021.104612 . hal-03256962

\section{HAL Id: hal-03256962 https://hal.science/hal-03256962}

Submitted on 10 Jun 2021

HAL is a multi-disciplinary open access archive for the deposit and dissemination of scientific research documents, whether they are published or not. The documents may come from teaching and research institutions in France or abroad, or from public or private research centers.
L'archive ouverte pluridisciplinaire HAL, est destinée au dépôt et à la diffusion de documents scientifiques de niveau recherche, publiés ou non, émanant des établissements d'enseignement et de recherche français ou étrangers, des laboratoires publics ou privés. 

duplication to synergy

Massimiliano Cardinale ${ }^{a, *}$, Francesco Colloca ${ }^{b}$, Angelo Bonanno ${ }^{c}$, Giuseppe Scarcella ${ }^{f}$, Enrico Arneri ${ }^{f}$, Angélique Jadaud ${ }^{\mathrm{p}}$, Claire Saraux ${ }^{\mathrm{h}}$, Salvatore Aronica ${ }^{\mathrm{c}}$, Simona Genovese ${ }^{\mathrm{c}}$, Marco Barra ${ }^{\mathrm{d}}$, Gualtiero Basilone $^{c}$, Silvia Angelini ${ }^{f}$, Fabio Falsone ${ }^{e}$, Vita Gancitano ${ }^{e}$, Alberto Santojanni ${ }^{f}$, Fabio Fiorentino ${ }^{e}$, Giacomo Milisenda', Matteo Murenu' ${ }^{\circ}$, Tommaso Russo ${ }^{\mathrm{g}}$, Piera Carpi ${ }^{j}$, Beatriz Guijarro', José Luis Pérez Gil ${ }^{k}$, María González ${ }^{k}$, Pedro Torres ${ }^{k}$, Ana Giráldez ${ }^{k}$, Cristina García ${ }^{k}$, Antonio Esteban ${ }^{n}$, Encarnación García ${ }^{n}$, Miguel Vivas $^{n}$, Enric Massutí, Francesc Ordines', Antoni Quetglas', Juan Gil Herrera ${ }^{m}$

${ }^{a}$ Department of Aquatic Resources, Institute of Marine Research, Swedish University of Agricultural Sciences, Turistgatan 5, 45330 Lysekil, Sweden

${ }^{\mathrm{b}}$ Stazione Zoologica Anton Dohrn, Department of Integrative Ecology, via Po 25c., 00198 Rome, Italy

${ }^{\mathrm{c}}$ Istituto per lo studio degli impatti Antropicie So stenibilità in ambiente marino (IAS), Consiglio Nazion ale delle Ricerche (CNR), SS of Capo Granitola, Campobello di Mazara, TP, Italy

${ }^{d}$ Istituto di Scienze Marine (ISM AR), Consiglio Nazion ale delle Ricerche (CNR) SS of Naples, Italy

${ }^{\mathrm{e}}$ Istituto per le Risorse Biologiche e le Biotecnologie Marine (IRBIM), Consiglio Nazion ale delle Ricerche (CNR), Mazara del Vallo, TP, Italy

${ }^{\mathrm{f}}$ Istituto per le Risorse Biologiche e le Biotecnologie Marine (IRBIM), Consiglio Nazion ale delle Ricerche (CNR), Ancona, AN, Italy

${ }^{\mathrm{g}}$ Laboratory of Experimental Ecology and Aquaculture, Department of Biology, University of Rome Tor Vergata, via Cracovia 1, 00133 Rome, Italy

${ }^{\mathrm{h}}$ Université de Strasbourg, CNRS, IPHC, UMR 7178 Strasbou rg, France

' Stazione zoologica Anton Dohrn, Integrative Marine Ecology, Lungomare Cristoforo Colombo, 90149

Palermo, Italy

${ }^{j}$ International Pacific Halibut Commission , 2320 West Commodore Way, Suite 300, Seattle, WA 981991287, USA

${ }^{k}$ Instituto Español de Oceanografía, Centro Oceanográfico de Málaga, Puerto Pesquero s/n Fuengirola, 29640 Málaga, Spain

'Instituto Español de Oceanografía, Centre Oceanogràfic de Balears, Mo II de Ponent s/n, 07015 Palma, Spain

${ }^{m}$ Instituto Español de Oceanografía, Centro Oceanográfico de Cádiz, Muelle de Levante s/n, Puerto Pesquero, 11006 Cádiz, Spain

${ }^{\mathrm{n}}$ Instituto Español de Oceanografía, Centro Oceanográfico de Murcia, Varadero, 1, San Pedro del Pinatar, 30740 Murcia, Spain

${ }^{\circ}$ Dipartimento di Scienze della Vita e dell'ambiente, Università di Cagliari, Italy

${ }^{\mathrm{p}}$ MARBEC, University of Montpellier, CNRS, Ifremer, IRD, Sète, France

*Corresponding author. E-mail address: massimiliano.cardinale@slu.se (M. Cardinale).

\section{Abstract}

Independence of science and best available science are fundamental pillars of the UN-FAO code of conduct for responsible fisheries and are also applied to the European Union (EU) Common Fishery Policy (CFP), with the overarching objective being the sustainable exploitation of the fisheries resources. CFP is developed by DG MARE, the department of the European Commission responsible for EU policy on maritime affairs and fisheries, which has the Scientific, Technical and Economic Committee for Fisheries (STECF) as consultant body. In the Mediterranean and Black Sea, the General Fisheries Commission for the Mediterranean (FAO-GFCM), with its own Scientific Advisory Committee on Fisheries (GFCM-SAC), plays a critical role in fisheries governance, having the authority to adopt binding recommendations for fisheries conservation and management. During the last years, advice on the status of the main stocks in the Mediterranean and Black Sea has been provided both by GFCM-SAC and EU-STECF, often without a clear 
coordination and a lack of shared rules and practices. This has led in the past to: i) duplications of the advice on the status of the stocks thus adding confusion in the management process and, ii) a continuous managers' interference in the scientific process by DG MARE officials hindering its transparency and independence. Thus, it is imperative that this stalemate is rapidly resolved and that the free role of science in Mediterranean fisheries assessment and management is urgently restored to assure the sustainable exploitation of Mediterranean marine resources in the future.

\section{Introduction}

The definition and adoption of measures for the sustainable management of fish stocks has become a priority worldwide due to overexploitation [1,2] and the ongoing climate change influence on fisheries resources $[3,4]$. The advisory process, which entails the assessment of fishing impact on fish stocks and ecosystems, is the core aspect of the entire procedure for identifying management measures aimed at the sustainable exploitation of fish stocks [5]. There are three main actors actively taking part in fisheries management: i) the scientists, who provide advices on fish stocks based on the most updated data, science and assessment methods, ii) decision makers, which take tactical decisions based on additional considerations (e.g. management objectives, economic aspects), and iii) stakeholders, such as fishers, industry representatives and non-governmental organizations, which provide support to the other two actors with additional data and different perspectives. With their constant interaction, the different actors identify management measures for the sustainable exploitation of fish stocks. However, this process could suffer from a number of pitfalls if clear rules are not established to regulate the role of each actor. When fish stocks are shared among different countries, the interaction among these countries further complicates the scene adding difficulties to the application of an evidence-based decision-making process. These interactions are even more complicated when countries involved are characterized by different levels of socio-economic development or geopolitical organization, such as in the Mediterranean region [6].

Worldwide, the advisory process is structured in different ways both at country and regional level, and generally relies on key principles highlighting the importance that conservation and management measures are based upon the best scientific information available and that scientific processes are free of undue non-scientific influences and considerations [see for example 7,8]. In each management area, the status of a number of selected fish and shellfish stocks is expected to be evaluated by expert working groups according to specific requests of the competent advisory body. Usually, the evaluation is based on the best available data, knowledge and methods. Once the advice on the status of the stocks is formally endorsed by the competent advisory body, decision makers are responsible for the definition, evaluation and adoption of management measures.

At regional level, States cooperate on fishery management through specific Regional Fishery Bodies (RFBs) such as the General Fisheries Commission for the Mediterranean (GFCM), the International Commission for the Conservation of Atlantic Tunas (ICCAT), the Northwest Atlantic Fisheries Organization (NAFO), the International Council for the Exploration of the Sea (ICES) and several others $[9,10]$. All RFBs provide scientific advice and support to fisheries management but not all of them have the mandate to take binding measures for fisheries management. The ICES is an example of this latter group. In ICES, all the steps leading to the advice, as well as the responsibilities and interactions among the involved actors are generally clearly defined and transparent. ICES advice, for example, is based on scientific recommendations subject to peer review by independent experts and it is prepared in an advice drafting group and approved by the Advisory Committee (ACOM) before being delivered to the advice recipients. On the contrary, 
GFCM has the authority to adopt binding recommendations for fisheries conservation and management. Every year, the representatives of the contracting parties of the GFCM review and adopt the recommendations developed on the basis of the advice provided by the GFCM subsidiary bodies, including its Scientific Advisory Committee on Fisheries (SAC), which provides technical and scientific advice for decisions related to fisheries management.

Although high variability in terms of governance exists both at the country and regional level, the independence of experts participating in working groups on stock assessment is considered a core principle of the process. Nevertheless, in some cases, such as GFCM, the interaction rules among actors (in terms of roles and responsibilities) are not always clearly defined. In this regard, the situation in the Mediterranean is further complicated by the occurrence of two different scientific advisory bodies, GFCM-SAC and STECF (Scientific, Technical and Economic Committee for Fisheries), the consultant body of DG MARE (the department of the European Commission responsible for EU policy on maritime affairs and fisheries), each one having its own advisory machinery, which has recently raised concerns on its efficiency on providing advice $[11,12]$. In this context, it is important to highlight that GFCM has competence for all marine waters of the Mediterranean and the Black Sea (http://www.fao.org/gfcm/about/area-of-application/en/) and has the authority to adopt conservation and management measures for the fisheries under its purview, which are binding on the contracting parties [13]. The EU as a contracting party is therefore obliged to comply with GFCM management decisions and not vice versa. The mandate of the GFCM-SAC is, among others, to provide independent advice in order to facilitate the adoption of recommendations concerning the sustainable management of fisheries and ecosystems at the regional and sub-regional levels. These recommendations encompass relevant biological, environmental, social and economic aspects in compliance with the ecosystem approach to fisheries, as well as aspects related to the impact of IUU (Illegal Unreported and Unregulated) fishing and the assessment of biological and ecological implications under different management scenarios (see: http://www.fao.org/gfcm/about/structure/sac/en/). Moreover, EU and non-EU countries are involved in the assessment process of several shared stocks, which means that only GFCM can deal with this additional complexity.

\section{Pitfalls in the Mediterranean fisheries advisory process}

\section{Duplication of advice on the status of the stocks}

The institutional forum for providing scientific advice on fisheries in the Mediterranean Sea is the GFCM-SAC, where scientists from EU and non-EU countries meet during dedicated working groups to provide advice on the status of Mediterranean and Black Sea stocks and ecosystems. The selection of the models to be used in stock assessment is guided by the stock characteristics and the type of data available to scientists. The assessments undergo a validation process and, once endorsed by the SAC, are presented to the policy makers during the annual meeting of the GFCM Commission, where specific management measures are discussed and eventually adopted.

In parallel, by means of a process similar to the one adopted by the GFCM-SAC, the same fish stocks in the EU waters are assessed also by the STECF through specific expert working groups (EWGs) [14]. EWGs work on official data prepared following DG MARE guidelines, and DG MARE also decides the specific term of references of the EWGs. The resulting assessments are reported to the STECF plenary where they are scrutinized by STECF members. The scientific advice of the STECF is then made available to EU managers and can be used in a wide framework of policy actions aimed to support the Common Fisheries Policy (CFP). Even if the work done by GFCM-SAC 
and STECF should theoretically results in an efficient fisheries resources management, complications arise because of the large overlap between the work done by the two bodies and because of the absence of a clear distinction of their respective roles during this process.

As a matter of fact, lack of coordination in the advisory process has often led to the duplication of GFCM-SAC work by the STECF, which has raised criticisms and debate within the scientific community $[11,12,15]$. In 2019, such situation has not changed and two competing assessments were performed for 15 stocks: one produced by the STECF and another one submitted by the national experts under the GFCM umbrella. Those included for example sole and cuttlefish in Geographical Sub Area (GSA) 17, red mullet in GSA 1 and 6, striped red mullet in GSA 5, Norway lobster in GSA 5 and blue and red shrimp in GSA 1. As a result, the GFCM Working Group on Demersal Species (WGSAD) held in Rome (Italy) on December 2019 [16], had to review all these duplicated 15 stock assessments to provide a sort of consensus report, a situation that not only has created a general sense of impasse, but also represents a waste of human resources and taxpayer money, as suggested by [11,12]. For example, several of those stock assessments (e.g. common sole), considered valid by STECF, were rejected by GFCM. Indeed, some attempts of developing common assessments between GFCM-SAC and STECF were carried out, i.e. the Adriatic hake benchmark in January 2019 and the evaluation of small pelagics (i.e. sardine and anchovy) in the Adriatic Sea, but with limited results, since STECF, for example, performed again in October 2019 the assessment of Adriatic hake. Moreover, in the case of shared stocks, STECF assessments have often failed to include all the available data and expertise since not all countries bordering the Mediterranean are EU Members [11]. It is important to note that while the development and production of alternative assessments would improve the science and the quality of the resulting advices, it raises two important issues. First, in the case of limited manpower, duplicating the work might be seen as a waste of human resources and a hinder to the provision of more assessments. Second, to actually improve the quality of the advice, it would require confronting the different models and assessments. This is generally done at GFCM benchmark assessment meetings in which one or more models are proposed and peer-reviewed by external referees (e.g. Adriatic hake (http://www.fao.org/gfcm/technical-meetings/detail/en/c/1194087/) and Sicilian Strait hake; (http://www.fao.org/gfcm/technical-meetings/detail/en/c/1274921/), and the best case model is chosen, based on scientific and technical basis agreed upon by experts, and then used for advice. However, this is not routinely happening for the Mediterranean stocks, as two different bodies (i.e. GFCM and STECF) provides two parallel stock assessments of the same stock resulting in two different advices, which we believe is an important obstacle for fisheries management. Differences in assessment results (even if the resulting stock status is the same) yield doubts for managers and discredit the advice, making the decision process more complicated.

\section{Managers' interference in the scientific process}

The independence of science and the adoption of decisions based on the best available science are fundamental principles both in UN-FAO and EU frameworks. In particular, according to the European Charter for Researchers (https://euraxess.ec.europa.eu/jobs/charter/european-charter), "Researchers should focus their research for the good of mankind and for expanding the frontiers of scientific knowledge, while enjoying the freedom of thought and expression, and the freedom to identify methods by which problems are solved, according to recognized ethical principles and practices". In EU countries these principles are observed in all sectors of science, technology and innovation, and clearly should also apply to the CFP. Unfortunately, those fundamental principles have been violated in recent years by DG MARE, intruding the scientific debate of GFCM-SAC working groups regarding to matters strictly related to research, such as the quality of the data 
and the models applied, thus going well beyond their institutional role [11,12]. This has happened also in STECF meetings, like the 2019 stock assessment working groups, where stocks were only assessed using a certain model and any other options was disregarded. Also within the GFCM-SAC working groups, there has been in several occasions the attempt of DG MARE to drive the scientific process, providing opinions on technical matters and trying to impose their views. A tendency culminated in the rejected proposal made by the EU-DG MARE delegation at the $43^{\text {rd }}$ Plenary Session of the GFCM to ban the use of "complex stock assessment models" in Mediterranean and Black Sea, insinuating that those models are too difficult for Mediterranean scientists to be used [17; points 133 and 134).

During the last two decades, knowledge about the impact of fishing exploitation and the status of fisheries resources and exploited ecosystems in the Mediterranean and Black Sea has improved consistently thanks to the effort done by both GFCM and EU in promoting data collection on fisheries, and application of models of increasing complexity $[18,19]$, but also promoting capacity building initiatives, such as the summer school in stock assessment organized in 2017-2019 by GFCM and STECF jointly. Stock assessment models, which are applied to achieve the GFCM and CFP objective to advance towards an Ecosystem Approach to Fisheries Management can range from single species models to multispecies or even holistic types of ecosystem models. In the Mediterranean, the provision of scientifically sound advice and the improvement of national capacity to provide assessment and management of fisheries, which also encompasses neighboring countries, are pillars of the GFCM mid-term strategy. In recent years, the GFCM has been moving towards increasingly complex models. The shift, which has also taken place in other regions of Europe such as the Northeast Atlantic, is driven by several objectives, among which the main are: i) to provide confidence intervals of the estimates; ii) to account for the complexity of the fishery system, which is often multispecies, multi-gear and multinational, and iii) to take into account other parts of the ecosystem and include environmental variables in the models as well as socio-economic aspects. In particular, this shift is progressively occurring in those Mediterranean fisheries where Multiannual Management Plans are in place or are expected to come into force in the near future. The shift towards more complex stock assessment models has been associated with a more thorough peer-reviewed benchmark assessment process within GFCM-SAC, conducted by highly qualified experts from outside the GFCM area, also with a view to adjust to practices that are commonly adopted all over the world. This is not the case for STECF, where assessments are not formally peer-reviewed and often accepted without consulting the regional experts.

\section{Moving toward a more effective and transparent advisory process}

The overarching objectives of the GFCM and CFP are to achieve the sustainable exploitation of fishing resources through the definition of a common target: the Maximum Sustainable Yield (MSY) and the Good Environmental Status (GES) of marine ecosystems. In the Mediterranean, these objectives have been adopted and are applied through the work carried out in the framework of the GFCM Mid-Term Strategy as well as through commendable EU initiatives like the MedFish4Ever declaration [20]. Particularly, the first pillar of the GFCM mid-term strategy (20172022) states: "Reverse the declining trend of fish stocks through strengthened scientific advice in support of management; (http://www.fao.org/gfcm/activities/fisheries/mid-term-strategy/en/)". The GFCM mid-term strategy was agreed by all member countries with the signature of the MedFish4Ever declaration (https://gfcmsitestorage.blob.core.windows.net/website/MedFish4Ever/2017-03-30-declaration- 
malta.pdf). However, in latest years the process necessary to achieve the overarching objectives of the CFP has been hindered by the lack of coordination between GFCM and DG MARE $[8,9]$. Thus, it is crucial to define a clear coordination process of the activities carried out by STECF and GFCMSAC, in order to shift from "duplication of working groups" to "synergy between working groups" $[11,12]$.

The possible solutions are numerous but in principle, STECF and GFCM-SAC should work under the same guidelines and according to common standardized and transparent procedures, with respect to the way stock assessments are conducted as well as how each advice is formulated. This would not only avoid duplication of work but also would strengthen the capacity of the whole advisory system towards the sustainable exploitation of marine resources and ecosystems, which is the ultimate objective of the CFP and of the GFCM following the United Nations Fish Stocks Agreement, and in line with the FAO Code of Conduct for Responsible Fisheries. Furthermore, the coordination process should be assisted by clearly defining the role of stakeholders (as for example DG MARE) in scientific and technical meetings such as stock assessment and benchmarks working groups of GFCM-SAC, through an ad hoc "policy document" (hereafter defined as the "GFCM policy document"). Institutions such as ICES (and, notably, DG MARE itself) have clear guidelines defining the role of participants in this kind of meetings. For instance, ICES assigns to advice recipients (such as DG MARE) very clear roles in stock assessment and benchmarks. In particular, they can participate as observers and can explain the meaning of their requests and intervene for policy-related matters, but have no say in methodological, technical or scientific questions, which are a prerogative of scientists (Mark Dickey-Collas, ICES ACOM Chair, personal communication). In particular, the "GFCM policy document" should clearly state which are the actors allowed to participate in the expert working groups, together with their roles, duties and responsibilities. Furthermore, the "GFCM policy document" should also single out that the advisory process has to meet criteria such as: i) scientific processes should be free of non-scientific influences and/or considerations; ii) all the documents, data and models should be made available to all actors for the sake of transparency; iii) scientific group results should be peer-reviewed by independent experts, possibly outside the Mediterranean area and, even best, outside Europe. This should hopefully end the past continuous interference of DG MARE in the GFCM scientific work.

In the Mediterranean Sea, the CFP and, more recently, the MSFD (Marine Strategy Framework Directory) continue to fall far short of their exploitation objectives [20,21,22]. The last GFCM reports on the Status of Mediterranean and Black Sea Fisheries [23] states that $75 \%$ of the assessed stocks is in a state of overexploitation and, that although the trend has been reversed, the level of exploitation is in general unsustainable. As a matter of fact, the current lack of coordination between GFCM-SAC and STECF and the absence of a clear definition of the roles of stakeholders in technical meetings has hindered the assessment of Mediterranean stocks and fueled the difficulties related to the already complex process of aligning management in the Mediterranean with the FAO-UN and EU-CFP sustainability targets. Thus, it is imperative that this impasse is urgently resolved and that the free role of scientists in Mediterranean fisheries science is restored. The current approach of DG MARE to GFCM is an exception when compared to how EU approach other international agreements (e.g., NAFO, ICCAT and IOTC) and ideally EU should contribute to and adopt GFCM scientific advice, without duplication from STECF. Thus, instead of hindering the process, the existence of two advice bodies, GFCM-SAC and STECF, should be a great strength to face the current challenges of fisheries management in the Mediterranean Sea by increasing the number of stocks that could be assessed and promoting synergies towards more 
methodological expertise and capacity building that could assure the sustainable exploitation of Mediterranean marine resources.

\section{References}

[1] FAO. The State of Mediterranean and Black Sea Fisheries. General Fisheries Commission for the Mediterranean, <www.fao.org/3/ca2702en/CA2702EN.pdf >, Rome, 2018.

[2] FAO. The State of World Fisheries and Aquaculture 2018 - Meeting the sustainable development goals. <www.fao.org/3/i9540en/i9540en.pdf>, Rome, 2018.

[3] É. Plagányi, Climate change impacts on fisheries, Science 363(6430) (2019) 930-931.

[4] R.Q. Grafton, Adaptation to Climate Change in Marine Capture Fisheries, Marine Policy 34(3) (2010) 606-615, DOI: 10.1016/j.marpol.2009.11.011.

[5] C.Walters, \& S.J. Martell, Stock assessment needs for sustainable fisheries management, Bulletin of Marine Science 70(2) (2002) 629-638.

[6] A.D. Smith, \& S.M. Garcia, Fishery management: contrasts in the Mediterranean and the Atlantic, Current Biology 24(17) (2014) R810-R812.

[7] J.R. Beddington, D.J. Agnew, \& C.W. Clark, Current problems in the management of marine fisheries, Science 316(5832) (2007) 1713-1716.

[8] E.D. Anderson, The history of fisheries management and scientific advice - the ICNAF/NAFO history from the end of World War II to the present, Journal of Northwest Atlantic Fishery Science 23 (1998) 75-94.

[9] E. Gilman, K. Passfield, \& K. Nakamura, Performance of regional fisheries management organizations: ecosystem-based governance of bycatch and discards, Fish and Fisheries 15(2) (2014) 327-351.

[10] D.A. Russell, \& D.L. VanderZwaag, Recasting Transboundary Fisheries Management Arrangements In Light Of Sustainability Principles, in: D.A. Russell, \& D.L. VanderZwaag, Recasting Transboundary Fisheries Management Arrangements in Light of Sustainability Principles (2011) 1-6.

[11] P. Carpi, G. Scarcella, and M. Cardinale, The saga of the management of fisheries in the Adriatic Sea: history, flaws, difficulties and successes towards the application of the common fishery policy in the Mediterranean. Front. Mar. Sci. 4 (423) (2017), doi: 10.3389/fmars.2017.00423.

[12] M. Cardinale, P.Carpi, and G. Scarcella, Response: Commentary: The Saga of the Management of Fisheries in the Adriatic Sea: History, Flaws, Difficulties, and Successes Toward the Application of the Common Fisheries Policy in the Mediterranean. Front. Mar. Sci. 6 (296) (2019) doi: 10.3389/fmars.2019.00296.

[13] EU 2019. Proposal for a COUNCIL DECISION concerning the position to be taken on behalf of the European Union in the General Fisheries Commission for the Mediterranean and repealing decision 9389/1/14 REV 1.

[14] A.C. Tsikliras, A. Dinouli, V.Z. Tsiros, \& E. Tsalkou, The Mediterranean and Black Sea fisheries at risk from overexploitation, PloS one 10(3) (2015).

[15] H. Dörner, and J. Casey, Commentary: the saga of the management of fisheries in the Adriatic Sea: history, flaws, difficulties, and successes toward the application of the common fisheries policy in the Mediterranean. Front. Mar. Sci. 5 (468) (2018) doi: 10.3389/fmars.2018.00468.

[16] GFCM 2019. Report of Working Group on Stock Assessment of Demersal Species (WGSAD). FAO headquarters, Rome, Italy, 9-14 December 2019. 69 pp. Available at: https://gfcm.sharepoint.com/:b:/g/EG/EWLHsgNGXZxJpAtyolJpt6wBd4LLG61jOelFdzdHUhtzo A. 
[17] GFCM, Report of the $43^{\text {rd }}$ Session of the General Fisheries Commission for the Mediterranean, <http://www.fao.org/gfcm/statutory-meetings/detail/en/c/1260370/>, 2019.

[18] D.K. Moutopoulos, S. Libralato, C. Solidoro, \& K.I. Stergiou, Toward an ecosystem approach to fisheries in the Mediterranean Sea: Multi-gear/multi-species implications from an ecosystem model of the Greek Ionian Sea, Journal of Marine Systems 113 (2013) 13-28.

[19] F. Colloca, G. Scarcella, \& S. Libralato, Recent trends and impacts of fisheries exploitation on Mediterranean stocks and ecosystems, Frontiers in Marine Science 4(244) (2017).

[20] GFCM, GFCM High-level conference on MedFish4Ever initiatives. $<$ http://www.fao.org/gfcm/meetings/medfish4ever/en/>, 2019.

[21] F. Colloca, M. Cardinale, F. Maynou, M. Giannoulaki, G. Scarcella, K. Jenko, J.M. Bellido, F. Fiorentino, Rebuilding Mediterranean fisheries: a new paradigm for ecological sustainability, Fish and Fisheries 14 (1) (2013) 89-109.

[22] P. Vasilakopoulos, C.D. Maravelias, G. Tserpes, The Alarming Decline of Mediterranean Fish Stocks, Current Biology 24 (2014) 1-6, doi: 10.1016/j.cub.2014.05.070.

[23] GFCM 2020. The state of Mediterranean and Black Sea fisheries 2020 at a glance. (http://www.fao.org/gfcm/publications/somfi/en/) 